\title{
Identification of galectin-7 as a potential biomarker for esophageal squamous cell carcinoma by proteomic analysis
}

\author{
Xi Zhu'1, Ming Ding³3, Mei-Lan Yu33, Ming-Xiang Feng*2, Li-Jie Tan² and Fu-Kun Zhao*1,3
}

\begin{abstract}
Background: Esophageal squamous cell carcinoma (ESCC) is one of the most common malignancies. Early diagnosis is critical for guiding the therapeutic management of ESCC. It is imperative to find more effective biomarkers of ESCC.

Methods: To identify novel biomarkers for esophageal squamous cell carcinoma (ESCC), specimens from 10 patients with ESCC were subjected to a comparative proteomic analysis. The proteomic patterns of ESCC samples and normal esophageal epithelial tissues (NEETs) were compared using two-dimensional gel electrophoresis. And differentially expressed proteins were identified using MALDI-TOF-MS/MS. For further identification of protein in selected spot, western blotting and immunohistochemistry were employed.
\end{abstract}

Results: Twelve proteins were up-regulated and fifteen proteins were down-regulated in the ESCC samples compared with the NEET samples. Up-regulation of galectin-7 was further confirmed by western blotting and immunohistochemistry. Furthermore, immunohistochemical staining of galectin-7 was performed on a tissue microarray containing ESCC samples $(n=50)$ and NEET samples $(n=10)$. The expression levels of galectin-7 were markedly higher in the ESCC samples than in the NEET samples $(P=0.012)$. In addition, tissue microarray analysis also showed that the expression level of galectin-7 was related to the differentiation of ESCC.

Conclusions: The present proteomics analysis revealed that galectin-7 was highly expressed in ESCC tissues. The alteration in the expression of galectin-7 was confirmed using a tissue microarray. These findings suggest that galectin7 could be used as a potential biomarker for ESCC.

\section{Background}

Esophageal carcinoma is one of the most malignant gastrointestinal cancers and is ranked the 6th leading cause of cancer death worldwide [1]. Esophageal squamous cell carcinoma (ESCC) is the predominant histological subtype of esophageal carcinoma in Asia [2]. The overall 5year survival rate of ESCC is less than 10\% [3]. One of the primary reasons for this high mortality rate is that ESCC is often not detected until it has invaded surrounding organs and is therefore at an advanced stage. Surgery is inappropriate in $40-60 \%$ of patients due to unresectable

*Correspondence: feng.mingxiang@zs-hospital.sh.cn, fkzhao@sibs.ac.cn

${ }^{1}$ Institute of Biochemistry and Cell Biology, Shanghai Institutes for Biological Sciences, Chinese Academy of Sciences, 320 Yue-Yang Road, Shanghai 200031, China

2 Department of Thoracic Surgery, Zhong Shan Hospital, Fu Dan University, Shanghai, 200032, China

Full list of author information is available at the end of the article disease status, the presence of distant metastases, or high operative risk [4]. Conventional chemotherapy and radiotherapy treatments are also relatively ineffective [5]. The odds of long-term survival are poor when the disease extends through the esophageal wall or when it is diagnosed with widespread lymph node involvement. Early diagnosis and exact histological grading of ESCC are therefore critical for guiding the therapeutic management of ESCC.

A biomarker is a molecule that indicates a pathological alteration in physiology. Cancer biomarkers can provide important information for cancer diagnosis and staging and give guidance in many areas, such as cancer therapy [6]. High-throughput and high-sensitivity proteomics technology provides an effective approach for screening novel cancer-specific biomarkers. Tissue-based proteomic analyses directly relate protein biomarkers to dis- 
ease and have been widely used in the study of various tumors [7-9]. In past years, molecules identified by proteomics, such as pRB protein, tropomyosin isoform 4 (TPM4), prohibitin and periplakin [10-14] have been reported as potential biomarkers for the diagnosis of ESCC. However, most of these molecules require experimental verification using clinical-scale sample sets before clinical application. Thus, it is still imperative to find more effective, clinically verified biomarkers of ESCC [15].

Galectins are a family of $\beta$-galactoside-binding lectins with diverse biological functions. Different galectin family members have been reported to be show significantly altered expression $[16,17]$ and play important roles in various types of cancer $[18,19]$. In a recent report, induction of galectin-1 expression by the human pituitary tumor transforming gene (PTTG) promoted lymph node metastasis in human ESCC [20]. Galectin-7, a member of the galectin family initially identified in human epider$\mathrm{mis}$, is a $15-\mathrm{kDa}$ protein with a single carbohydrate recognition domain [21,22]. Expression of galectin-7 is restricted to stratified epithelial cells including the skin, tongue, esophagus and Hassal's corpuscles in the thymus [23]. The major functions of galectin-7 include regulation of cell-cell and cell-matrix interactions, apoptosis and immunity $[16,24,25]$. Growing evidence indicates that galectin-7 plays an important role in cancer progression [26-28]. Galectin-7 has been reported to function as an important molecule in the dissemination and invasion of lymphoma cells in human lymphoid malignancies [29]. It is also involved in muscle infiltration of urothelial cancer [30]. However, the expression pattern of galectin-7 in ESCC tissue is still unknown.

In this study, a proteomics approach was used to analyze the different proteomic patterns in ESCC and NEET samples. After comparing the expression patterns, differentially expressed proteins between them were identified. Among these proteins, galectin-7 was found to be highly expressed in ESCC tissues. Confirmatory studies have been done to examine the possibility of galectin- 7 to be a biomarker for ESCC.

\section{Methods \\ Materials}

The ESCC specimens were obtained from 10 patients who undergone surgery in the thoracic surgery department of Zhongshan Hospital. All ESCC patients undergone curative resection and were not treated with neoadjuvant chemotherapy or radiotherapy. The clinical staging was performed according to the tumor-nodemetastasis classification system. The overall clinicopathological data of the cases are listed in Table 1. Matched normal mucosal tissues located at least $5 \mathrm{~cm}$ away from the tumor margins were also included in this study. Two additional groups of ESCC cases were used in this work, 16 cases for immunohistochemistry, 50 cases for tissue microarray, which included 12 cases categorized as highly differentiated, 14 cases categorized as moderately differentiated, 13 cases categorized as poorly differentiated, and other cases in which pathologists did not reach a consensus as to the degree of differentiation. Freely tendered informed consent was obtained from all patients. The study was approved by the local ethics committee of Zhongshan Hospital.

The IEF system (IPGphor), ImmobilineDryStrips (24 $\mathrm{cm}, \mathrm{pH} 3-10 \mathrm{NL}$ ) and CLEAN-UP Kits were purchased from Amersham Biosciences. Iodoacetamide was obtained from Sigma-Aldrich (St. Louis, MO). The MS experiments were carried out using an ABI 4700 MALDITOF/TOF mass spectrometer (Applied Biosystems, Framingham, MA). Sequence-grade trypsin was obtained from Promega (Madison, WI, USA), and the standard peptide mixture used for calibration was obtained from Applied Biosystems. All buffers were prepared with MilliQ water.

\section{Sample preparation}

Each tissue sample was crushed and ground in a mortar containing liquid nitrogen. The resulting powder was immediately suspended in a lysis buffer $(7 \mathrm{M}$ urea, $2 \mathrm{M}$ thiourea, 4\% CHAPS, $65 \mathrm{mM}$ DTT, 2\% IPG buffer, and trace cocktail protease inhibitor). After the solution was vigorously stirred for $1 \mathrm{hr}$, the cell debris and insoluble substances were removed by centrifugation at $100,000 \mathrm{~g}$ for $45 \mathrm{~min}$. Protein concentrations were determined using a modified Bradford method [31]. The supernatant was aliquoted and stored at $-80^{\circ} \mathrm{C}$ for further use.

\section{Two-dimensional electrophoresis (2-DE)}

Seven batches of tissue samples were subjected to 2-DE. 2-DE was carried out according to the manufacturer's instructions [32] with minor modifications. Briefly, 200 $\mu \mathrm{g}$ of protein sample was diluted to $450 \mu \mathrm{L}$ with a rehydration solution (7 M urea, $2 \mathrm{M}$ thiourea, $0.2 \% \mathrm{DTT}, 0.5 \%$ [v/v] pH 3-10 IPG buffer and a trace of bromphenol blue) and applied to IPG strips $(24 \mathrm{~cm}, \mathrm{pH} 3-10 \mathrm{NL})$ in a 14-h rehydration. Proteins were focused on an IPGphor IEF system (Amersham Biosciences) for a total of $61 \mathrm{kVh}$. The two-dimensional separation was performed on $12.5 \%$ polyacrylamide gels with an Ettan DALT twelve apparatus (Amersham Biosciences) at $25^{\circ} \mathrm{C}$. Protein spots in the gels were visualized by silver staining as described by Yan et al [33] with minor modifications.

\section{Image analysis}

Silver-stained 2-DE gels were scanned using a D2000 Uniscan scanner (Tsinghua Uniscan, Beijing, China) with 
Table 1: Clinicopathological data of the 10 ESCC cases

\begin{tabular}{llllllll}
\hline Sample No. & Age & Gender & Site & Pathological grade & Size $(\mathbf{c m})$ & $\begin{array}{l}\text { Lymphatic } \\
\text { invasion }\end{array}$ & TNM stage \\
\hline 1 & & & & & Negative & II \\
2 & 58 & Male & Upper & Moderately differentiated & 3 & Positive & III \\
3 & 67 & Female & Middle & Moderately differentiated & 5 & Negative & I \\
4 & 55 & Male & Middle & Well differentiated & 2 & Negative & I \\
5 & 62 & Male & Middle & Moderately differentiated & 2 & Negative & II \\
6 & 62 & Male & Upper & Moderately differentiated & 2.5 & Negative & II \\
7 & 52 & Male & Middle & Poorly differentiated & 4 & Positive & IV \\
8 & 61 & Male & Middle & Moderately differentiated & 3 & Positive & III \\
9 & 55 & Female & Lower & Poorly differentiated & 6 & Positive & II \\
\hline
\end{tabular}

300-dpi resolution and analyzed using ImageMaster ${ }^{\mathrm{TM}} 2 \mathrm{D}$ Platinum software (Version 5.0; Amersham Bioscience). To guarantee the reliability of the results, the gel images of seven batches of samples were imported to ImageMas$\operatorname{ter}^{\mathrm{TM}}$ 2D Platinum software simultaneously. Protein spots were automatically detected. Individual spot volumes were normalized against total spot volumes. Alignment and matching of the spots were carried out by choosing one gel as a reference and by manually selecting one common spot as a landmark. Two-sample t-tests were used to analyze differences in protein expression between the ESCC and NEET groups. Fold changes more than 1.5 and $P$ values less than 0.05 were considered statistically significant.

\section{In-gel digestion and MS}

The selected protein spots were excised from the gels and incubated in a silver-destaining solution containing 30 $\mathrm{mM}$ potassium ferricyanide and $100 \mathrm{mM}$ sodium thiosulfate $(1: 1)$ for $10 \mathrm{~min}$ at room temperature. The samples were washed twice with Milli-Q water and once with 25 $\mathrm{mM}$ ammonium bicarbonate $/ 50 \%$ acetonitrile (ACN). The samples were then dehydrated in $100 \%(\mathrm{v} / \mathrm{v}) \mathrm{ACN}$ and dried in a speed-vacuum. After drying, the samples were rehydrated on ice for $45 \mathrm{~min}$ in $2.5 \mu \mathrm{l}$ of $25 \mathrm{mM}$ $\mathrm{NH}_{4} \mathrm{HCO}_{3}$ containing $10 \mathrm{ng} / \mathrm{l}$ sequencing-grade trypsin (Promega, Madison, WI). The rehydrated gel spots were digested for $4 \mathrm{hrs}$ at $37^{\circ} \mathrm{C}$. The peptide fragments were extracted with $5 \%$ TFA and $2.5 \%$ TFA $/ 50 \% \mathrm{ACN}$ in succession. The supernatants were pooled, dried, and recovered in $1.5 \mu \mathrm{L}$ of $0.5 \%$ TFA. Finally, the digested peptide samples were co-crystallized with an equal volume of saturated matrix solution (CHCA in $0.1 \%$ TFA in $\mathrm{H}_{2} \mathrm{O} / \mathrm{ACN}$ [2:1]) on the MALDI sample target plate. Peptide mass spectra were obtained with a MALDI-TOF/TOF mass spectrometer (4700 Proteomics Analyzer, Applied Biosystems).

The protein spots were identified by MS and MS/MS as described by Tian et al [34]. Prior to real sample acquisition, six external standards (mass standard kit for the 4,700 proteomics analyzer calibration mixture, Applied Biosystems) were used to calibrate each spectrum to a mass accuracy of within 5 ppm for the MS Reflector Positive Operating Mode or within $10 \mathrm{ppm}$ for the MS-MS 1 KV Positive Operating Mode. A combined database search of MS and MS/MS measurements was performed using GPS Explorer ${ }^{\mathrm{TM}}$ software (Version 3.5; Applied Biosystems) and MASCOT software (Version 2.0; Matrix Science, London, UK). Searches were performed with carbamidomethylation of cysteine and oxidation of methionine as variable modifications. One trypsin miscleavage was allowed. The peptide mass tolerance and fragment mass tolerance were set to $50 \mathrm{ppm}$ and $\pm 0.1 \mathrm{Da}$, respectively. Peptide mixtures that yielded statistically significant search scores (> 95\% C.I., equivalent to MASCOT expected value $<0.05$ ) and accounted for the majority of ions present in the mass spectra were defined as positive identifications.

\section{Western blotting}

For validation experiments, a new set of tissue samples was collected for immunoblotting analysis of galectin-7. All protein samples for validation were separated by SDSPAGE with $20 \mu \mathrm{g}$ protein per lane and transferred onto a PVDF membrane (Millipore) in transfer buffer ( $\mathrm{pH} 11.0$, $25 \mathrm{mM}$ Tris, $0.2 \mathrm{M}$ glycine, 20\% [v/v] methanol) for 45 min at $1.5 \mathrm{~mA} / \mathrm{cm}^{2}$ on a semidry electroblotter (Bio-Rad). After being blocked with $1 \%$ skim milk for $1 \mathrm{hr}$ at $25^{\circ} \mathrm{C}$, galectin-7 was detected by incubating the samples with a goat polyclonal anti-galectin-7 antibody at a 1:300 dilution (R\&D Systems, Minneapolis, MN) overnight at $4^{\circ} \mathrm{C}$. 
Horseradish peroxidase-conjugated rabbit anti goat Ig at a 1:3,000 dilution (AMS Biotechnology, Oxon, UK) was used as a secondary antibody. The immunoblots were developed using ECL detection reagent (Pierce Chemical).

\section{Immunohistochemistry}

Immunohistochemistry was performed on formalinfixed, paraffin-embedded tissue sections using a standard immunohistochemical technique. Four-micrometer-thick tissue sections were deparaffinized in xylene, rehydrated in a graded ethanol series and treated with an antigen retrieval solution (10 mM sodium citrate buffer; $\mathrm{pH}$ 6.0). The sections were incubated with a goat polyclonal antigalectin-7 antibody (dilution 1:125) overnight at $4^{\circ} \mathrm{C}$ and then incubated with a 1:1,000 dilution of biotinylated secondary antibody, followed by avidin-biotin peroxidase complex (DAKO), according to the manufacturer's instructions. Finally, tissue sections were incubated with 3,3'-diaminobenzidine (Sigma-Aldrich) until a brown color developed, and the sections were then counterstained with Harris modified hematoxylin. For the negative controls, the primary antibodies were omitted.

\section{Tissue microarray}

The tissue microarray slides (Shanghai Biochip Company, Ltd., Shanghai, China) contained 120 formalin-fixed, paraffin-embedded tissue samples, including 50 ESCC tissues, 10 NEET samples. Each sample had two sample dots. Immunohistochemistry for galectin-7 was performed using the avidin-biotin complex method (ABC; Vector Laboratories, Burlingame, CA), including heatinduced antigen-retrieval procedures. Incubation with polyclonal antibodies against galectin-7 (1:100 dilution; R\&D Systems, Minneapolis, MN) was done at $48^{\circ} \mathrm{C}$ for 18 hours. Fourteen negative controls were treated identically but with the primary antibody omitted.

\section{Evaluation of galectin-7 expression}

The German immunohistochemical scoring (GIS) system was applied to estimate galectin-7 expression. The GIS system is a semiquantitative scoring system in which the final immunoreaction score is expressed as the product of the intensity and quantity scores. The extent percentage of positive cells was graded as follows: 0 , negative; $1,<$ $10 \%$ positive cells; $2,11 \%$ to $50 \%$ positive cells; $3,51 \%$ to $80 \%$ positive cells; $4,>80 \%$ positive cells. The staining intensity was graded as follows: 0 , negative; 1 , weakly positive; 2 , moderately positive; and 3 , strongly positive. GIS score $\geq 6$ was defined as high expression. GIS score $<6$ was defined as low expression. All staining was independently evaluated by three different pathologists who were blinded to patient outcomes. Statistical analysis of GIS scores was done using SigmaPlot software. $P$ values less than 0.05 were considered statistically significant.

\section{Results}

2-DE proteome maps of NEET and ESCC specimens

The proteomic profiles of the ESCC and NEET samples were examined using 2-DE. After silver nitrate staining, $2-\mathrm{DE}$ images with high resolution and reproducibility were obtained. Representative 2-DE images are shown in Figure 1. To ensure reliability and reproducibility, seven batches of tissue samples were subjected to proteomic analysis using ImageMaster 2D Platinum Version 5.0 software and fourteen gels were generated. Twenty-seven protein spots had significantly different expression patterns between the two groups $(>1.5$-fold change, $P<0.05$; Figure 1). Relative to the NEET group, the expression levels of 12 protein spots were markedly increased and 15 protein spots were decreased in the ESCC group. The zoom-in and 3D quantified views showed some representative differentially expressed protein spots between the two types of tissues (Figure 2A). The statistical analysis of the volumes (\% volume) of these spots from seven batches of tissue samples is shown in Figure 2B.

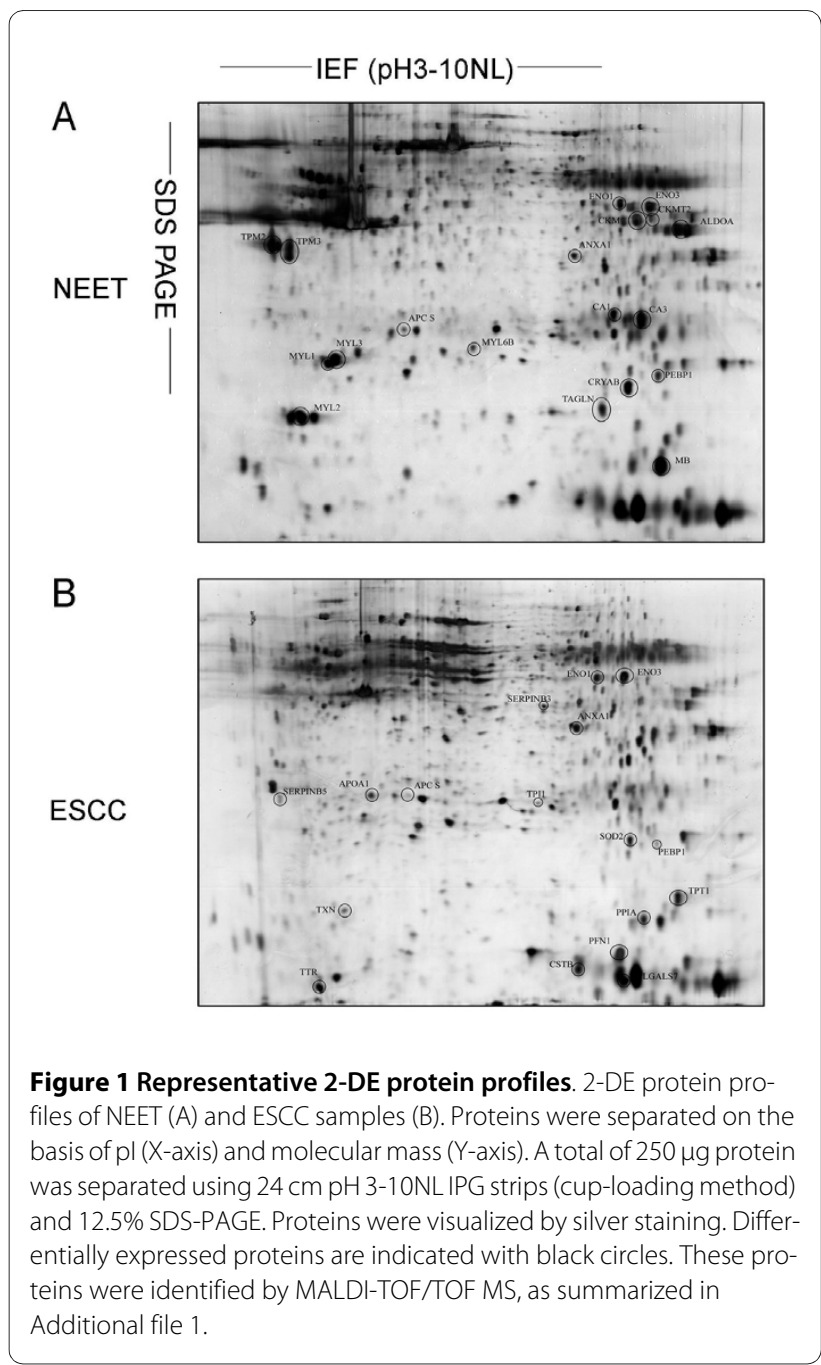




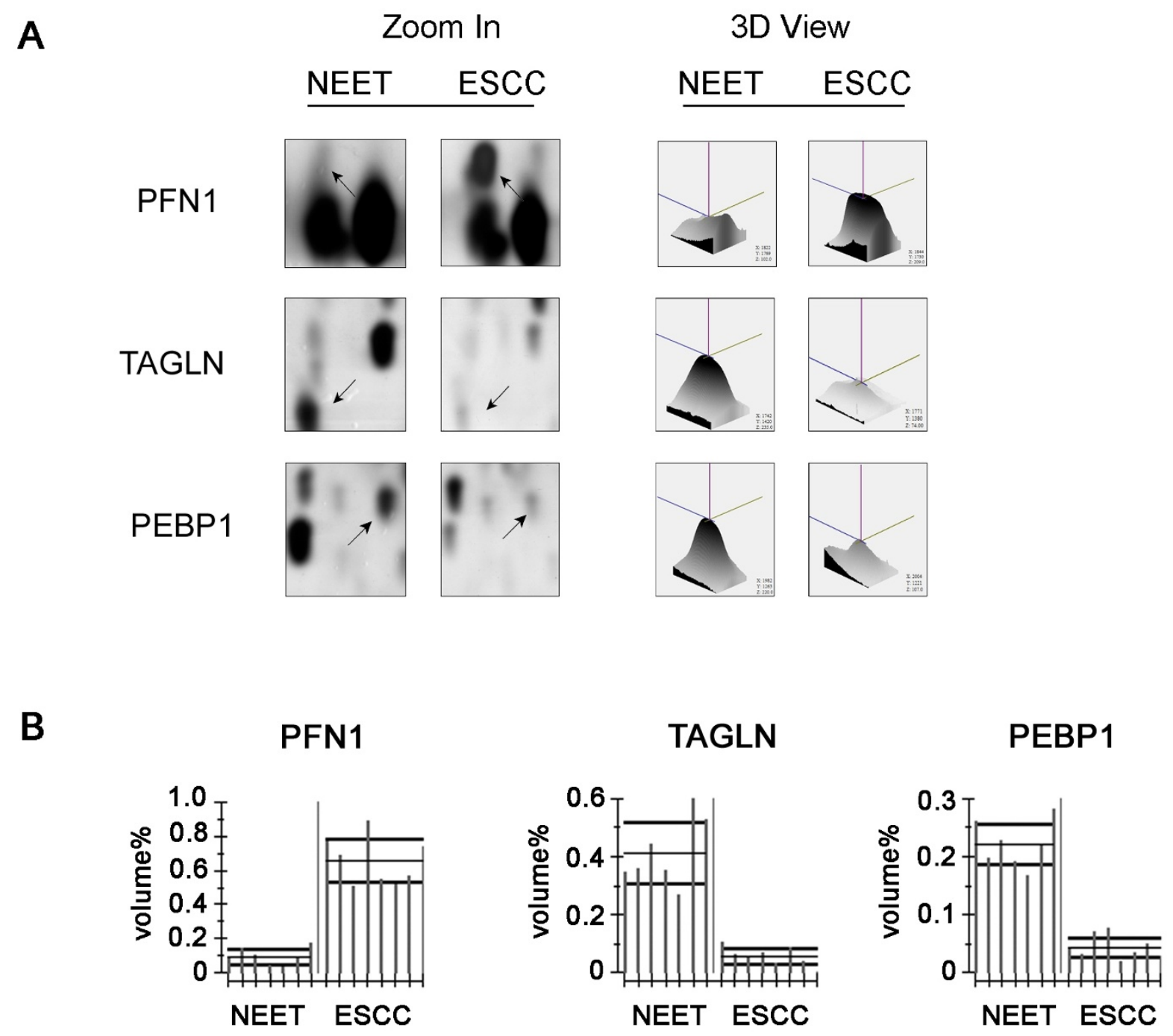

Figure 2 Comparative analysis of representative proteins with altered expression patterns in NEET and ESCC cells. (A) Magnified comparison maps and quantified 3D views. (B) Statistical analyses of the protein spots.

Identification of differentially expressed proteins using MALDI-TOF/TOF mass spectrometry and functional exploration of candidate proteins

To characterize the differentially expressed proteins, the 2-DE spots were excised from the silver-stained gels and analyzed by MALDI-TOF mass spectrometry. The peptide mass fingerprints (PMF) of the differentially expressed proteins were acquired in the MS Reflector Positive Operating Mode and then subjected to SwissProt database searching using GPS Explorer ${ }^{\mathrm{TM}}$ software. To further confirm the MS identification results, four peaks with the strongest signals in the MS spectra were automatically selected and subjected to MS/MS analysis. MS and MS/MS identification of each differentially expressed protein from different batches of 2-DE gels were repeated at least three times. As a representative example, the PMF and MS/MS spectra of galectin-7 are illustrated in Figure 3 . The matched amino acid sequences of galectin-7 are underlined. Three precursor peptides of $\mathrm{m} / \mathrm{z} 857.4628$, 1399.7379 and 2511.1833 were confirmed as the tryptic peptides of galectin-7. The amino acid sequences of these peptides identified by MS/MS were "76GPGVPFQR ${ }^{83 ",}$ "100AVVGDAQYHHFR111", and "33FHVNLLCGEEQGSD AALHFNPR ${ }^{54 " . ~ A d d i t i o n a l ~ f i l e ~} 1$ (Identification of proteins differentially expressed in esophageal cancer specimens by MALDI-TOF MS and MS/MS) summarizes the identified proteins and their gene names, Swiss-Prot accession numbers, theoretical molecular weights/p $I$ val- 


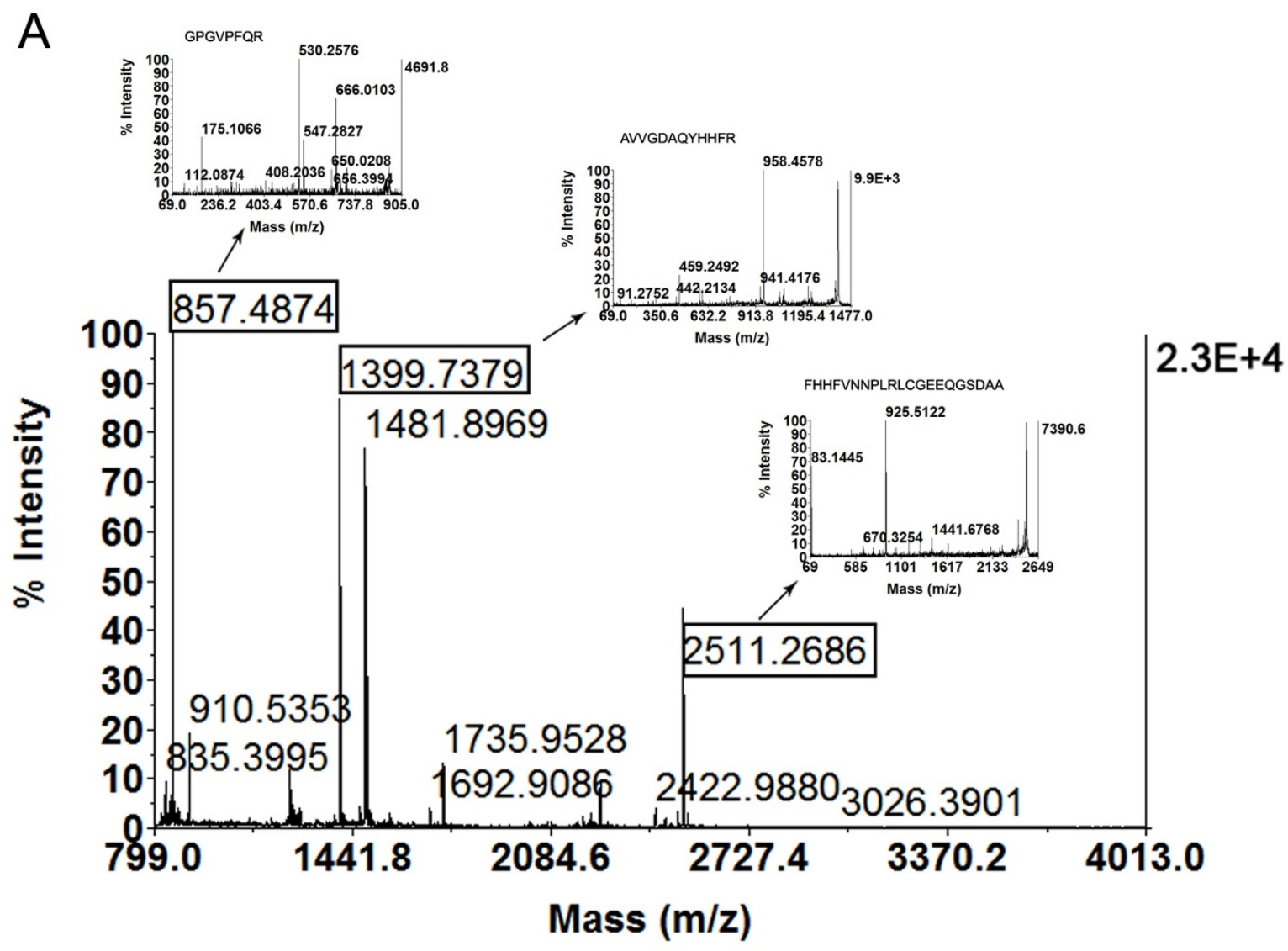

B

Figure 3 Identification of galectin-7 by MALDI-TOF/TOF mass spectrometry. (A) Peptide mass fingerprints of galectin-7 are shown. Matched peptide peaks are labeled with mass values, and the sequences of precursor peptides with $\mathrm{m} / \mathrm{z} 857.4628,1399.7379$ and 2511.1833 were confirmed using MALDI-TOF MS/MS. (B) Amino acid sequences of galectin-7. Matched peptides are underlined.

ues, mascot scores, peptide counts, coverage (\%), sequence confirmation by MS/MS and MS/MS scores.

The expression patterns of differentially expressed proteins in esophageal cancer specimens and their biological functions are shown in additional file 2: Expression patterns of differentially expressed proteins in esophageal cancer specimens and their biological functions. Regulatory factors and statistics are also included in additional file 2 . The identified proteins were classified into 8 func- tional categories based on their molecular functions and biological processes according to the KEGG and ExPasy http://www.expasy.org/sprot/ databases (See additional file 3: Functional classification of proteins). Approximately $27 \%$ of the proteins are involved in metabolism, including energy, carbohydrate, nucleotide and lipid metabolism. Cell growth and death (20\%) and cytoskeletal (19\%) functions accounted for the second and third categories of proteins, respectively. Proteins involved in 
signal transduction (11\%), folding (9\%), transcription (8\%) and transport (2\%) were also identified.

\section{Validation by western blotting and immunohistochemistry}

The proteins identified by mass spectrometry such as annexin A1, tropomyosin, profiling 1 , translationally controlled tumor protein and serpin B3 have been previously reported to be altered in malignancies [14,35-39]. However, the expression level of most of them have not been studied in ESCC. Among the differentially expressed proteins in ESCC, we decided to focus on further confirming the expression patterns of Glectin-7, whose expression levels have not been well studied in human esophageal cancers and whose change in its expression could potentially be served as a marker for ESCC. To confirm the differential expression pattern of galectin-7, additional samples were examined by western blotting and immunohistochemistry. Consistent with the 2-DE data, the western blotting results (See additional file 4: Western blotting results of galectin-7 expression in several pairs of ESCC and NEET samples) showed elevated expression levels of galectin-7 in the ESCC samples relative to the NEET samples (Figure 4B).

Immunohistochemical staining also showed that galectin-7 is highly expressed in ESCC tissues relative to NEET samples. Furthermore, the expression of galectin-7 was distributed in the cytoplasm, nuclei and membranes of ESCC cells, whereas it was distributed primarily in only the nuclei of NEET cells (Figure 4C). The sub-cellular localization and expression of galectin-7 were examined by immunofluorescence staining in four ESCC cell lines as well (See additional file 5: Sub-cellular localization of galectin-7 in four ESCC cell lines). These results, taken together with the proteomics observations, suggest that galectin-7 is up-regulated in ESCC tissues, which further support that galectin-7 could be served as a potential marker for ESCC.

\section{Tissue microarray}

To further investigate the clinical significance of the differential expression of galectin-7 in ESCC tissues, we extended our studies by performing tissue microarray evaluations on a larger patient population. Figure 5 displays representative images of immunostaining for galectin-7. In 10 NEET samples, negative $(\mathrm{n}=2,20 \%)$, very weak $(\mathrm{n}=7,70 \%)$ or weak $(\mathrm{n}=1,10 \%)$ expression of galectin-7 was detected. In contrast, high expression of galectin-7 was detected in 28 of 50 (56.0\%) ESCC samples. The fold difference of galectin-7 expression in ESCC versus NEET samples was $2.5(P=0.012)$ (Figure 5$)$.

In 50 cases of ESCC, 12 cases were diagnosed as being well differentiated, 14 were diagnosed as moderately differentiated and 13 were diagnosed as poorly differenti- ated. We excluded the analysis of 6 cases of carcinoma in situ and 5 cases in which pathologists did not reach a consensus as to the degree of differentiation. Two groups divided by high or low expression were considered for statistical analysis. The most differentiated (grade I) ESCC samples showed a strong positive signal for galectin-7. Conversely, poorly differentiated (grade III) ESCC samples showed relatively low galectin-7 expression. A statistically significant association was observed between galectin-7 expression level and the differentiation of human ESCC $(P=0.045)$ (Table 2). Taken together, these results indicate that galectin-7 is up-regulated in ESCC and that its expression is related to the differentiation of ESCC.

\section{Discussion}

This study was designed to isolate and identify ESCC biomarkers using proteomic tools. Using 2-DE and mass spectrometry, we have successfully identified 27 proteins with different expression patterns in ESCC tissues. In previous ESCC proteomics studies, several differentially expressed proteins such as transgelin and tropomyosin were identified [14]. Among these 27 proteins, there are also several proteins we are interested, and may be further investigated, such as galectin-7, PEBP1, profilin1, TCTP and triosephosphate isomerase. Among them, galectin-7 was found to be rarely reported differentially expression in ESCC before. Besides, some reports showed that galectin-7 expression altered during the tumour progression in some kinds of carcinomas $[27,29,40]$. So, among these differentially expressed proteins, galectin-7 was selected for further verification and investigation.

There are several reports of galectin-7 expression in human cancers [30,41]. However, these reports suggest conflicting roles of galectin-7 in cancer progression [14]; galectin-7 appears to have dual roles, with anti- and promalignant features, and different expression levels in different cancers. Galectin-7 expression can be induced by p53 transfection in a human colon carcinoma cell line. Therefore, galectin-7 has been designated p53-induced gene 1 (PIG1) [42]. The anti-tumor roles of galectin-7 are associated with induction of apoptosis [43] or inhibition of cell proliferation [44]. In contrast, other reports have demonstrated that galectin-7 is up-regulated in other cancers such as hypopharyngeal squamous cell carcinoma [27]. One mechanism of the pro-tumor role of galectin-7 may involve induction of MMP-9, which plays an important role in cancer progression and metastasis [45]. Although proteomics has been used previously to characterize the molecular background of ESCC, this is the first report of an up-regulation of galectin-7 in ESCC tissues. Furthermore, the up-regulation was confirmed by 
A

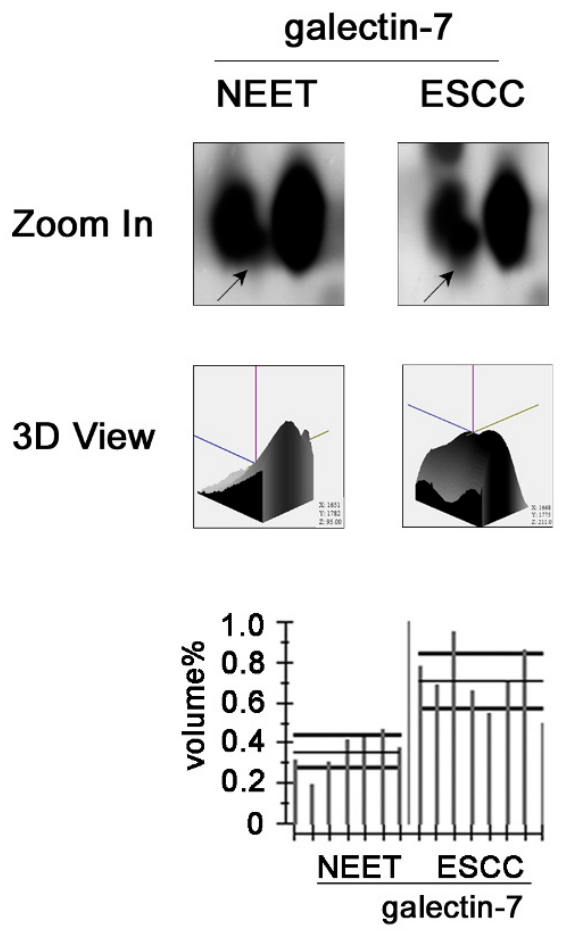

C

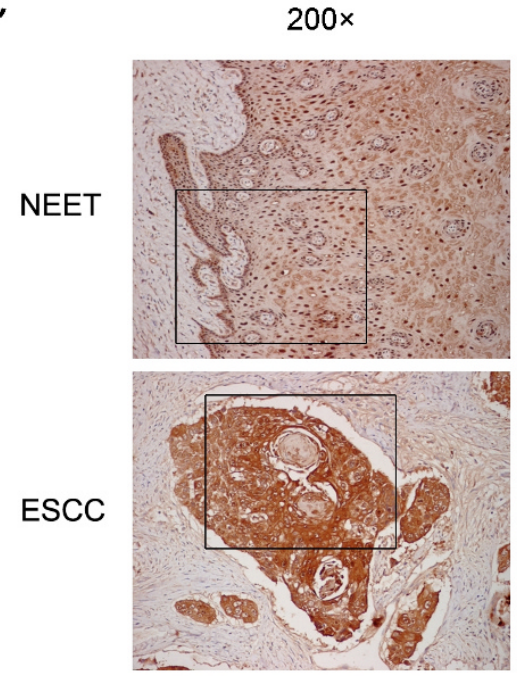

B
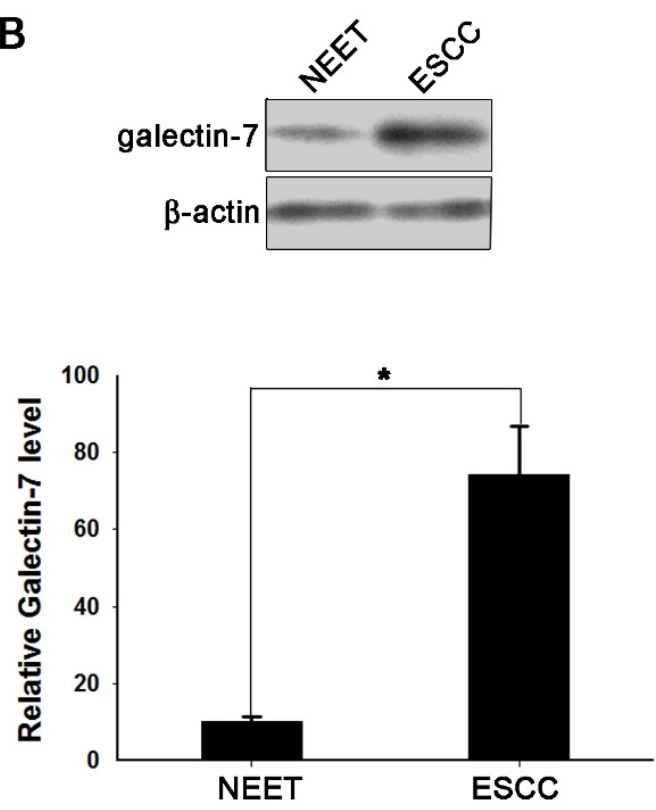

Figure 4 Expression of galectin-7 is up-regulated in ESCC tissues relative to NEET tissues. (A) The magnified comparison maps, quantified 3D views and statistical analyses of galectin-7 expression in NEET and ESCC samples. (B) Representative samples of ESCC and NEET were resolved on 10\% polyacrylamide gels and immunoblotted with an anti-galectin-7 antibody and a $\beta$-actin antibody as a loading control. The intensity of each band was measured with GraphPad Prism 4.0 software, and relative galectin-7 protein levels between ESCC and NEET samples were normalized against those of $\beta$-actin. The expression of galectin-7 was increased in tumor tissues. The difference in galectin-7 expression between ESCC and NEET samples was assessed using Student's $t$-test $\left({ }^{*} P<0.05\right)$ for unpaired values. (C) Immunohistochemical analysis of galectin-7 expression in ESCC. Galectin-7 displayed positive staining in ESCC samples that was much stronger than the staining in non-neoplastic tissue. In normal esophageal epithelial tissues, galectin7 is localized primarily to the nucleus. Expression of galectin-7 was detected ubiquitously in the cytoplasm, nuclei and membranes of ESCC cells. Images in the left panel were taken under 200x magnification; the right panel images are $400 \times$ magnifications of the same sections depicted on the left. 


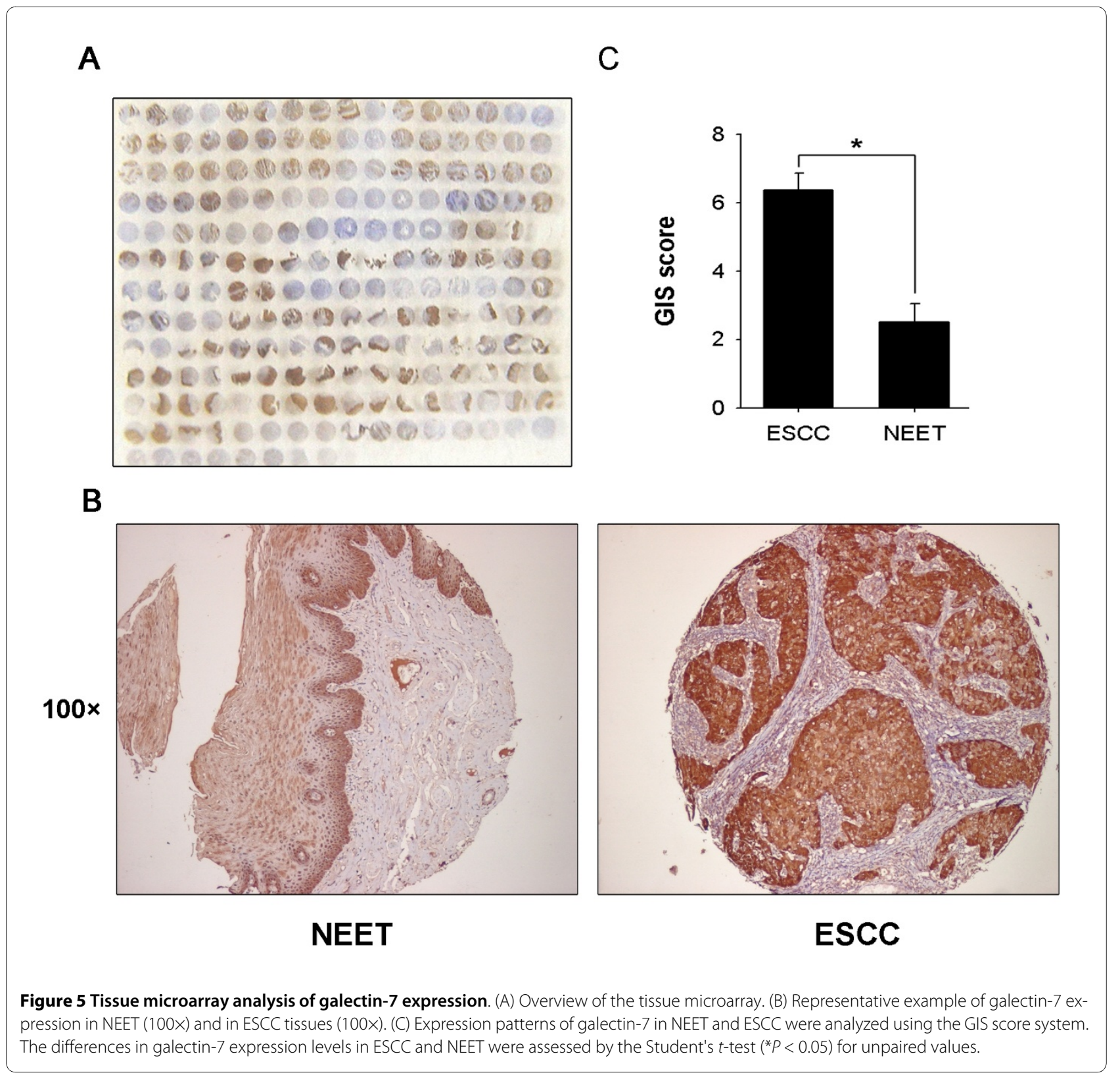

western blotting and immunohistochemistry of clinical sample sets. Due to the epithelial of esophagus is one of restricted regions expressing galectin-7 [23], it is possible that the different expression pattern has special role in the progression of ESCC. Collectively, these results indicate that galectin-7 is a potential biomarker for ESCC.

We found that the level of galectin-7 expression was related to the degree of ESCC differentiation. The welldifferentiated (grade I) ESCC samples showed a stronger positive signal for galectin-7 compared with poorly differentiated (grade III) ESCC samples. Because galectin-7 acts downstream of the p53 anti-tumor gene, up-regulation of galectin-7 expression in the early stages of ESCC progression may be a mechanism of organ self-protection. Consistent with our findings, other reports have indicated that galectin-7 has different expression pattern in the different degree of tumor differentiation in bladder squamous cell carcinoma [46] and glyctin-7 has both anti- and pro-malignant characteristics at different stages in the progression of thyroid cancer [40]. Because one of the main reasons for the high mortality rate of ESCC is that it is not detected until it has invaded surrounding organs and is at an advanced stage, the special up-regulation of galectin-7 in ESCC may be useful as a diagnosis marker of ESCC. 
Table 2: Comparison of ESCC differentiation degree with galectin-7 expression

\begin{tabular}{llll}
\hline Expression level & \multicolumn{1}{c}{ Differentiation degree } & poorly \\
\cline { 2 - 4 } & well & moderately & 10 \\
\hline low & 4 & 5 & 3 \\
high & 8 & 9 & 0.045 \\
\hline High expression levels correspond to tumors with either intense homogeneous or intense inhomogeneous Gal-7-dependent staining signals.
\end{tabular}

Low expression levels correspond to tumors with either weak homogeneous staining signals or no detectable Gal-7 signal.

In this study, we found that galectin-7 was primarily localized in the nuclei of NEET cells, whereas it was distributed throughout the cytoplasm, nuclei and membranes of ESCC cells. The intracellular localization of certain proteins may be associated with tumor progression. For example, nuclear localization of galectin-7 was associated with the initiation of tumorigenesis in laryngeal squamous cell carcinomas [27]. Additionally, galectin-3 was localized to the nuclei of ESCC cells [47]. These results suggest that tumor progression of ESCC may be associated with a translocation of galectin- 7 from the nucleus to the cytoplasm.

\section{Conclusions}

Using proteomic analysis, we have identified galectin-7 as a potential biomarker of ESCC. Furthermore, we have confirmed the alteration in the expression of galectin- 7 using a tissue microarray. These results strongly suggest that galectin-7 is involved in the development of ESCC and could potentially be served as a marker for ESCC.

\section{Additional material}

Additional file 1 Identification of proteins differentially expressed in esophageal cancer specimens by MALDI-TOF MS and MS/MS. The figure is in the portable document format (Identification.pdf). Mascot MS scores were taken from the MS spectra search results using GPS Explorer software (Version 3.5). In this program, a Mascot score $>45$ was considered significant.

Additional file 2 Expression patterns of differentially expressed proteins in esophageal cancer specimens and their biological functions. The table is in the excel spreadsheet format (function.xls). (a) Ratio of protein expression level is the statistical analysis of the results from seven batches of 2D gels using ImageMasterTM software. (b) Biological function is based on the information from KEGG and ExPasy database.

Additional file $\mathbf{3}$ Functional classification of proteins. The figure is in the portable document format (classification.pdf). Functional classification of differentially expressed proteins based on information from KEGG and ExPasy.

Additional file 4 Western blotting result of galectin-7 expression in several pairs of ESCC and NEET samples. The figure is in the JPEG format (westernblot.jpg). Six representative pairs of tissue samples were resolved on $10 \%$ polyacrylamide gels and immunoblotted with an anti-galectin-7 antibody and a $\beta$-actin antibody as a loading control. T, tumour; N, normal.
Additional file $\mathbf{5}$ Sub-cellular localization of galectin-7 in four ESCC cell lines. The figure is in the JPEG format (immunofluorescence.jpg). The sub-cellular localization and expression of Galectin-7 were examined by immunofluorescence staining in four ESCC cell lines, including KYSE 30, KYSE 70, KYSE 410 and TE-1. Cells were cultured on chamber slides, fixed with 4\% paraformaldehyde in PBS, permeabilized using 0.2\% Triton X-100, blocked using 3\%BSA, and stained with anti-galectin-7(R\&D Systems, Minneapolis, MN) as the primary antibody and DyLightTM549 conjugated antigoat lgG(Thermo Fisher Scientific, Inc) as the second antibody. DAPI staining was used as inner control. Fluorescence images were collected and analyzed by laser scanning confocal microscopy (Nikon ECLIPSE TE2000-E). Expression of galectin-7 protein was detected ubiquitously in the cytoplasm, nuclei and membranes in four ESCC cell lines, which were consistent with the results of immunohistochemistry assay.

\section{Competing interests}

The authors declare that they have no competing interests.

\section{Authors' contributions}

ZX and MXF initiated the study, participated in its design and coordination, carried out the study, performed the statistical analysis, and drafted the manuscript. FKZ and LJT were responsible for the experimental design and financial support. MD and MLY participated in sample preparation, trypsin digestion and MS identification. All authors read and approved the final manuscript.

\section{Acknowledgements}

We are grateful to Hong-Yu Tian and Xia Gao for their expert technical assistance.

\section{Author Details}

${ }^{1}$ Institute of Biochemistry and Cell Biology, Shanghai Institutes for Biological Sciences, Chinese Academy of Sciences, 320 Yue-Yang Road, Shanghai 200031, China, 2Department of Thoracic Surgery, Zhong Shan Hospital, Fu Dan University, Shanghai, 200032, China and ${ }^{3}$ College of Life Science, Zhejiang SciTech University, Hangzhou 310018, China

Received: 18 December 2009 Accepted: 15 June 2010

Published: 15 June 2010

\section{References}

1. Pisani P, Parkin DM, Bray F, Ferlay J: Erratum: Estimates of the worldwide mortality from 25 cancers in 1990. Int. J. Cancer, 83, 18-29 (1999). Int J Cancer 1999, 83(6):870-873.

2. Lehrbach DM, Nita ME, Cecconello I: Molecular aspects of esophageal squamous cell carcinoma carcinogenesis. Arq Gastroenterol 2003, 40(4):256-261

3. Katlic MR, Wilkins EW Jr, Grillo HC: Three decades of treatment of esophageal squamous carcinoma at the Massachusetts General Hospital. J Thorac Cardiovasc Surg 1990, 99(5):929-938.

4. Hagymasi K, Tulassay Z: Genetic background of esophageal squamous cell carcinoma. Orv Hetil 2007, 148(38):1795-1800. 
5. Tachibana M, Kinugasa S, Hirahara N, Yoshimura H: Lymph node classification of esophageal squamous cell carcinoma and adenocarcinoma. Eur J Cardiothorac Surg 2008, 34(2):427-431.

6. Sung $\mathrm{HJ}$, Cho JY: Biomarkers for the lung cancer diagnosis and their advances in proteomics. BMB Rep 2008, 41(9):615-625.

7. Cheung PK, Woolcock B, Adomat H, Sutcliffe M, Bainbridge TC, Jones EC, Webber D, Kinahan T, Sadar M, Gleave ME, et al: Protein profiling of microdissected prostate tissue links growth differentiation factor 15 to prostate carcinogenesis. Cancer Res 2004, 64(17):5929-5933.

8. Ebert MP, Kruger S, Fogeron ML, Lamer S, Chen J, Pross M, Schulz HU, Lage $\mathrm{H}$, Heim S, Roessner A, et al:: Overexpression of cathepsin B in gastric cancer identified by proteome analysis. Proteomics 2005, 5(6):1693-1704.

9. Roessler M, Rollinger W, Mantovani-Endl L, Hagmann ML, Palme S, Berndt $P$, Engel AM, Pfeffer $M$, Karl J, Bodenmuller $H$, et al:: Identification of PSME3 as a novel serum tumor marker for colorectal cancer by combining two-dimensional polyacrylamide gel electrophoresis with a strictly mass spectrometry-based approach for data analysis. Mol Cell Proteomics 2006, 5(11):2092-2101.

10. Hatakeyama H, Kondo T, Fujii K, Nakanishi Y, Kato H, Fukuda S, Hirohashi S: Protein clusters associated with carcinogenesis, histological differentiation and nodal metastasis in esophageal cancer. Proteomics 2006, 6(23):6300-6316.

11. Nishimori T, Tomonaga T, Matsushita K, Oh-Ishi M, Kodera Y, Maeda T, Nomura F, Matsubara H, Shimada H, Ochiai T: Proteomic analysis of primary esophageal squamous cell carcinoma reveals downregulation of a cell adhesion protein, periplakin. Proteomics 2006, 6(3):1011-1018.

12. Zhang LY, Ying WT, Mao YS, He HZ, Liu Y, Wang HX, Liu F, Wang K, Zhang DC, Wang Y, et al:: Loss of clusterin both in serum and tissue correlates with the tumorigenesis of esophageal squamous cell carcinoma via proteomics approaches. World J Gastroenterol 2003, 9(4):650-654.

13. Contu SS, Contu PC, Damin DC, Fagundes RB, Bevilacqua F, Rosa AS, Prolla $J C$, Moreira LF: pRB expression in esophageal mucosa of individuals at high risk for squamous cell carcinoma of the esophagus. World J Gastroenterol 2007, 13(11):1728-1731.

14. Qi Y, Chiu JF, Wang L, Kwong DL, He QY: Comparative proteomic analysis of esophageal squamous cell carcinoma. Proteomics 2005, 5(11):2960-2971.

15. Chen Y, Ouyang GL, Yi H, Li MY, Zhang PF, Li C, Li JL, Liu YF, Chen ZC, Xiao ZQ: Identification of RKIP as an invasion suppressor protein in nasopharyngeal carcinoma by proteomic analysis. J Proteome Res 2008, 7(12):5254-5262.

16. Liu FT: Galectins: a new family of regulators of inflammation. Clin Immunol 2000, 97(2):79-88.

17. Liu FT, Patterson RJ, Wang JL: Intracellular functions of galectins. Biochim Biophys Acta 2002, 1572(2-3):263-273.

18. Hernandez JD, Baum LG: Ah, sweet mystery of death! Galectins and control of cell fate. Glycobiology 2002, 12(10):127R-136R.

19. Rabinovich GA: Galectins: an evolutionarily conserved family of animal lectins with multifunctional properties; a trip from the gene to clinical therapy. Cell Death Differ 1999, 6(8):711-721.

20. Yan S, Zhou C, Lou X, Xiao Z, Zhu H, Wang Q, Wang Y, Lu N, He S, Zhan Q, et al: PTTG overexpression promotes lymph node metastasis in human esophageal squamous cell carcinoma. Cancer Res 2009, 69(8):3283-3290.

21. Madsen P, Rasmussen HH, Flint T, Gromov P, Kruse TA, Honore B, Vorum H, Celis JE: Cloning, expression, and chromosome mapping of human galectin-7. J Biol Chem 1995, 270(11):5823-5829.

22. Magnaldo T, Bernerd F, Darmon M: Galectin-7, a human 14-kDa S-lectin, specifically expressed in keratinocytes and sensitive to retinoic acid. Dev Biol 1995, 168(2):259-271.

23. Magnaldo T, Fowlis D, Darmon M: Galectin-7, a marker of all types of stratified epithelia. Differentiation 1998, 63(3):159-168.

24. Barondes SH, Cooper DN, Gitt MA, Leffler H: Galectins. Structure and function of a large family of animal lectins. J Biol Chem 1994, 269(33):20807-20810.

25. Hughes RC: Secretion of the galectin family of mammalian carbohydrate-binding proteins. Biochim Biophys Acta 1999, 1473(1):172-185.

26. Saussez S, Cucu DR, Decaestecker C, Chevalier D, Kaltner H, Andre S, Wacreniez A, Toubeau G, Camby I, Gabius HJ, et al: Galectin 7 (p53induced gene 1): a new prognostic predictor of recurrence and survival in stage IV hypopharyngeal cancer. Ann Surg Oncol 2006, 13(7):999-1009.

27. Saussez S, Decaestecker C, Lorfevre F, Chevalier D, Mortuaire G, Kaltner H, Andre S, Toubeau G, Gabius HJ, Leroy X: Increased expression and altered intracellular distribution of adhesion/growth-regulatory lectins galectins- 1 and -7 during tumour progression in hypopharyngeal and laryngeal squamous cell carcinomas. Histopathology 2008, 52(4):483-493.

28. Chen J, He QY, Yuen AP, Chiu JF: Proteomics of buccal squamous cell carcinoma: the involvement of multiple pathways in tumorigenesis. Proteomics 2004, 4(8):2465-2475.

29. Demers M, Biron-Pain K, Hebert J, Lamarre A, Magnaldo T, St-Pierre Y: Galectin-7 in lymphoma: elevated expression in human lymphoid malignancies and decreased lymphoma dissemination by antisense strategies in experimental model. Cancer Res 2007, 67(6):2824-2829.

30. Langbein S, Brade J, Badawi JK, Hatzinger M, Kaltner H, Lensch M, Specht K, Andre S, Brinck U, Alken P, et al: Gene-expression signature of adhesion/growth-regulatory tissue lectins (galectins) in transitional cell cancer and its prognostic relevance. Histopathology 2007, 51(5):681-690.

31. Ramagli LS: Quantifying protein in 2-D PAGE solubilization buffers. Methods Mol Biol 1999, 112:99-103.

32. Berkelman TST: 2-D Electrophoresis: using Immobilized pH Gradients; Principles \& Methods. Uppsala, Sweden: Amersham Biosciences; 1998.

33. Yan JX, Wait R, Berkelman T, Harry RA, Westbrook JA, Wheeler CH, Dunn MJ: A modified silver staining protocol for visualization of proteins compatible with matrix-assisted laser desorption/ionization and electrospray ionization-mass spectrometry. Electrophoresis 2000, 21(17):3666-3672.

34. Tian HY, Zhang KH, Gao X, Lei WW, Zhang L, Yu ML, Song JG, Zhao FK: Comparative proteomic analysis of cell cycle-dependent apoptosis induced by transforming growth factor-beta. Biochim Biophys Acta 2009.

35. Shen D, Nooraie F, Elshimali Y, Lonsberry V, He J, Bose S, Chia D, Seligson $D$, Chang HR, Goodglick L: Decreased expression of annexin A1 is correlated with breast cancer development and progression as determined by a tissue microarray analysis. Hum Pathol 2006, 37(12):1583-1591.

36. Garcia Pedrero JM, Fernandez MP, Morgan RO, Herrero Zapatero A, Gonzalez MV, Suarez Nieto C, Rodrigo JP: Annexin A1 down-regulation in head and neck cancer is associated with epithelial differentiation status. Am J Pathol 2004, 164(1):73-79.

37. Pawlak G, McGarvey TW, Nguyen TB, Tomaszewski JE, Puthiyaveettil R, Malkowicz SB, Helfman DM: Alterations in tropomyosin isoform expression in human transitional cell carcinoma of the urinary bladder. Int J Cancer 2004, 110(3):368-373.

38. Janke J, Schluter K, Jandrig B, Theile M, Kolble K, Arnold W, Grinstein E, Schwartz A, Estevez-Schwarz L, Schlag PM, et al: Suppression of tumorigenicity in breast cancer cells by the microfilament protein profilin 1. J Exp Med 2000, 191(10):1675-1686.

39. Srisomsap C, Subhasitanont P, Otto A, Mueller EC, Punyarit P, WittmannLiebold B, Svasti J: Detection of cathepsin B up-regulation in neoplastic thyroid tissues by proteomic analysis. Proteomics 2002, 2(6):706-712.

40. Rorive S, Eddafali B, Fernandez S, Decaestecker C, Andre S, Kaltner $H$, Kuwabara I, Liu FT, Gabius HJ, Kiss R, et al:: Changes in galectin-7 and cytokeratin-19 expression during the progression of malignancy in thyroid tumors: diagnostic and biological implications. Mod Pathol 2002, 15(12):1294-1301

41. Cada Z, Chovanec M, Smetana K, Betka J, Lacina L, Plzak J, Kodet R, Stork J, Lensch M, Kaltner H, et al:: Galectin-7: will the lectin's activity establish clinical correlations in head and neck squamous cell and basal cell carcinomas? Histol Histopathol 2009, 24(1):41-48

42. Polyak K, Xia Y, Zweier JL, Kinzler KW, Vogelstein B: A model for p53induced apoptosis. Nature 1997, 389(6648):300-305.

43. Bernerd F, Sarasin A, Magnaldo T: Galectin-7 overexpression is associated with the apoptotic process in UVB-induced sunburn keratinocytes. Proc Natl Acad Sci USA 1999, 96(20):11329-11334.

44. Kopitz J, Andre S, von Reitzenstein C, Versluis K, Kaltner H, Pieters RJ, Wasano K, Kuwabara I, Liu FT, Cantz M, et al: Homodimeric galectin-7 (p53-induced gene 1) is a negative growth regulator for human neuroblastoma cells. Oncogene 2003, 22(40):6277-6288. 
45. Saussez S, Cludts S, Capouillez A, Mortuaire G, Smetana K Jr, Kaltner H, Andre S, Leroy X, Gabius HJ, Decaestecker C: Identification of matrix metalloproteinase- 9 as an independent prognostic marker in laryngeal and hypopharyngeal cancer with opposite correlations to adhesion/growth-regulatory galectins-1 and -7. Int J Oncol 2009, 34(2):433-439.

46. Ostergaard M, Rasmussen $\mathrm{HH}$, Nielsen HV, Vorum H, Orntoft TF, Wolf H, Celis JE: Proteome profiling of bladder squamous cell carcinomas: identification of markers that define their degree of differentiation. Cancer Res 1997, 57(18):4111-4117.

47. Shibata T, Noguchi T, Takeno S, Takahashi Y, Fumoto S, Kawahara K: Impact of nuclear galectin-3 expression on histological differentiation and vascular invasion in patients with esophageal squamous cell carcinoma. Oncol Rep 2005, 13(2):235-239.

\section{Pre-publication history}

The pre-publication history for this paper can be accessed here: http://www.biomedcentral.com/1471-2407/10/290/prepub

doi: $10.1186 / 1471-2407-10-290$

Cite this article as: Zhu et al., Identification of galectin-7 as a potential biomarker for esophageal squamous cell carcinoma by proteomic analysis BMC Cancer 2010, 10:290

Submit your next manuscript to BioMed Central and take full advantage of:

- Convenient online submission

- Thorough peer review

- No space constraints or color figure charges

- Immediate publication on acceptance

- Inclusion in PubMed, CAS, Scopus and Google Scholar

- Research which is freely available for redistribution

Submit your manuscript at www.biomedcentral.com/submit
C) Biomed Central 